\title{
Erratum to: A Comparison of Online Versus Workbook Delivery of a Self-Help Positive Parenting Program
}

\author{
Matthew R. Sanders • Cassandra K. Dittman • \\ Susan P. Farruggia • Louise J. Keown
}

Published online: 15 August 2014

(C) Springer Science+Business Media New York 2014

\section{Erratum to: J Primary Prevent (2014) 35:125-133 DOI 10.1007/s10935-014-0339-2}

An author (Matthew R. Sanders) of the original publication wishes to include the following Conflict of Interest disclosure:

The Triple $\mathrm{P}$-Positive Parenting Program is owned by the University of Queensland (UQ). The University through its main technology transfer company UniQuest Pty Limited, has licensed Triple P
International Pty Ltd to disseminate the program worldwide. Royalties stemming from this dissemination activity are distributed to the Parenting and Family Support Centre, School of Psychology, UQ; Faculty of Health and Behavioural Sciences at UQ; and contributory authors. No author has any share or ownership in Triple P International Pty Ltd. Matthew Sanders is the founder and an author on various Triple $\mathrm{P}$ programs and a consultant to Triple $\mathrm{P}$ International.

The online version of the original article can be found under doi:10.1007/s10935-014-0339-2.

M. R. Sanders $(\bowtie) \cdot$ C. K. Dittman

Parenting and Family Support Centre, School of Psychology, University of Queensland, Brisbane, QLD 4072, Australia

e-mail: m.sanders@psy.uq.edu.au

M. R. Sanders · S. P. Farruggia - L. J. Keown

School of Learning, Development, and Professional

Practice, University of Auckland, Auckland, New Zealand 